Article

\title{
Assessing Private Investment in African Renewable Energy Infrastructure: A Multi-Criteria Decision Analysis Approach
}

\author{
Kenny Baumli ${ }^{\dagger}$ and Tooraj Jamasb *,† \\ Department of Economics, Copenhagen School of Infrastructure (CSEI), Copenhagen Business School, \\ Porcelænhaven 16A, 2000 Frederiksberg, Denmark; kenbaumli@gmail.com \\ * Correspondence: tj.eco@cbs.dk \\ + These authors contributed equally to this work.
}

Received: 6 October 2020; Accepted: 6 November 2020; Published: 12 November 2020

check for updates

\begin{abstract}
Energy poverty remains prevalent in many African countries, hindering economic development and exacerbating social inequalities. Simultaneously, population growth throughout the continent is expected to perpetuate the already high demand for basic energy services into the coming decades. Private sector finance is increasingly regarded as a necessary ingredient to remedy Africa's energy challenges and to stimulate the adoption of renewable energy. However, investments remain insufficient for the burgeoning infrastructure requirements of the African economies. This paper seeks to delineate the financial and non-financial drivers of investment decisions to understand better the barriers to private participation in African renewable energy projects. Using a fuzzy Technique for Order Preference by Similarity to Ideal Solution (TOPSIS) approach, we evaluate country-level characteristics and their influence on investor decisions. Investor confidence in regulatory effectiveness is identified as the primary concern for investors. Local capacity building and policy instruments, designed to overcome institutional rigidities, are among the preferred solutions. The findings indicate that non-financial drivers contribute to understanding Africa's private energy investment challenges.
\end{abstract}

Keywords: renewable energy; investment; multi-criteria decision making; Africa

JEL Classification: Q4; Q2; G1; G2; H4

\section{Introduction}

Energy poverty remains one of Africa's most significant barriers to socioeconomic progress. More than 600 million households lack access to essential energy services and population growth is expected to perpetuate existing shortages in the coming decades [1]. Insufficient public funding of regional power infrastructure is a determinant for entrenched social inequalities. Inadequate electricity supply restricts the availability of lighting, industrial innovations and development of social institutions, which moderates the quality of education and pace of economic development. Several studies elucidate a cointegration between energy accessibility, consumption and per capita incomes [2]. Frequent power outages and constraints on supply have been associated to the large dependency of costly captive diesel generators [3]. High mortality rates throughout the continent have also been attributed to the persistent reliance on biofuels by households [4].

The shortage of public investment in the power sector reflects macroeconomic and microeconomic challenges, including subdued capital market development, ineffective fiscal management, and the concentration of state ownership in the sector [5]. Whilst public funding constitutes the primary source of financing for power projects in the region, investment in new capacity has been limited. Identifying 
the levels which encourage private sector participation in domestic markets is necessary to address the supply deficits (p. 228, [6]).

A large body of literature highlights the importance of implementing power sector reforms in African economies [7]. Regulatory changes have been particularly salient in the promotion of external investment to the generation segment of energy markets. However, have generally lacked social legitimacy [8]. Although barriers to efficiency remain, the number of Independent Power Producer (IPP) projects and total investment have increased in countries pursuing reforms. Subsequently, mobilizing private sector participation is not only necessary to reduce the infrastructure investment gap but, given the right framework and incentives, can drive the development of renewable energy deemed critical for the sustainable development of African economies.

Extensive research predicating solutions for increasing the external sources of finance, frequently highlight a combination of non-financial and financial drivers. Whilst the uncompetitive risk-reward profiles of African renewable energy projects have contributed to the shortage of private investment, various non-financial criteria can explain the preferences of these investors [9]. Moreover, this set of criteria also determine the range of possible projects from which a financial decision is made. Consequently, cognitive biases may preclude African energy projects from being considered during the early-stages of the assessment; during the perception and formulation of alternatives. The dissemination of information by a decision-maker is, for example, dependent on the interdependence of his/her a-priori beliefs, extent of institutional pressure, knowledge about the operating context and attitude towards radical innovation [10]. Subsequently, focusing on financial drivers without acknowledging the behaviors and the expected responses of investors overlooks an important aspect of research.

The paper contributes to research in several ways. First, the identification of investment decision making criteria help to understand better the characteristics which motivate private investments in renewable energy projects. Second, the delineation of non-financial and financial drivers is important for designing policies aimed at mobilizing external sources of investment. Finally, the paper reinforces the relevance of Multi-Criteria Decision Making (MCDM) methodologies as a practical tool for understanding complex investment decisions. The paper fills a gap in the literature by introducing a fuzzy TOPSIS approach to identify the drivers of investment and to delineate the significance of financial and non-financial criteria on the evaluation of African renewable energy projects. We posit that although financial incentives and drivers are necessary to encourage greater participation, domestic policies need to have tangible effects on investor confidence. We specifically address the attitudes of the private sector to regulatory commitment and solutions based on local capacity building. A market-based mechanism to disintermediate governance issues and address institutional rigidities, which exacerbate regional energy challenges, are among the prescriptions in the paper.

The remainder of the paper is as follows: Section 2 reviews private investment in African renewable energy projects. Section 3 introduces the research approach of the paper and the MCDM methodology of the empirical analysis. Section 4 describes the primary data used in the study. Section 5 discusses the main findings, offers policy recommendations and concludes.

\section{Private Investment in African Renewable Energy Projects}

\subsection{Investment Gap}

Insufficient financing of power infrastructure capacity, and the disparity of electricity sector development, is among Africa's greatest challenges. Whilst estimates vary, the requirements for improving energy quality and access are expected to exceed USD 45 billion a year [7]. Similar observations have been made by the European Investment Bank (EIB), suggesting energy infrastructure upgrades, and new capacity, are likely to constitute up to $6.5 \%$ of continental GDP in the coming decades. Importantly, funding shortages primarily relate to the provision of new capacity and not the 
maintenance of existing facilities. Consequently, the investment gap is best thought of as the difference in 'investment needs' and 'actual investment'.

The determinants of investment needs include the shortages in energy services provision and rising consumer demand attributed to the increase in per capita incomes and population growth [1]. In part, the consequences of the investment gap have been offset by investment from domestic and international institutions. Whilst the investment needs are great, the significant causes of Africa's investment gap are the drivers of actual investment. Ref. [6] considers factors such as access to finance, macroeconomic policies, technical capacity and policy objectives as determinants of domestic spending on infrastructure projects.

Further, Ref. [11] finds issues related to legislative and regulative complexity, arising from the lack of coherent frameworks and bureaucracy, impact the flow of actual investment from the private sector. These determinants are emblematic of institutional quality issues in many African countries, reflecting aspects of political instability, corruption, fragmentation and the level of business complexity $[12,13]$. Figure 1 shows that African countries experience low levels of government effectiveness (scores closer to 2.5 are preferred), substantiating the relevance of institutional quality concerns as possible explanations for the lack of actual investment.

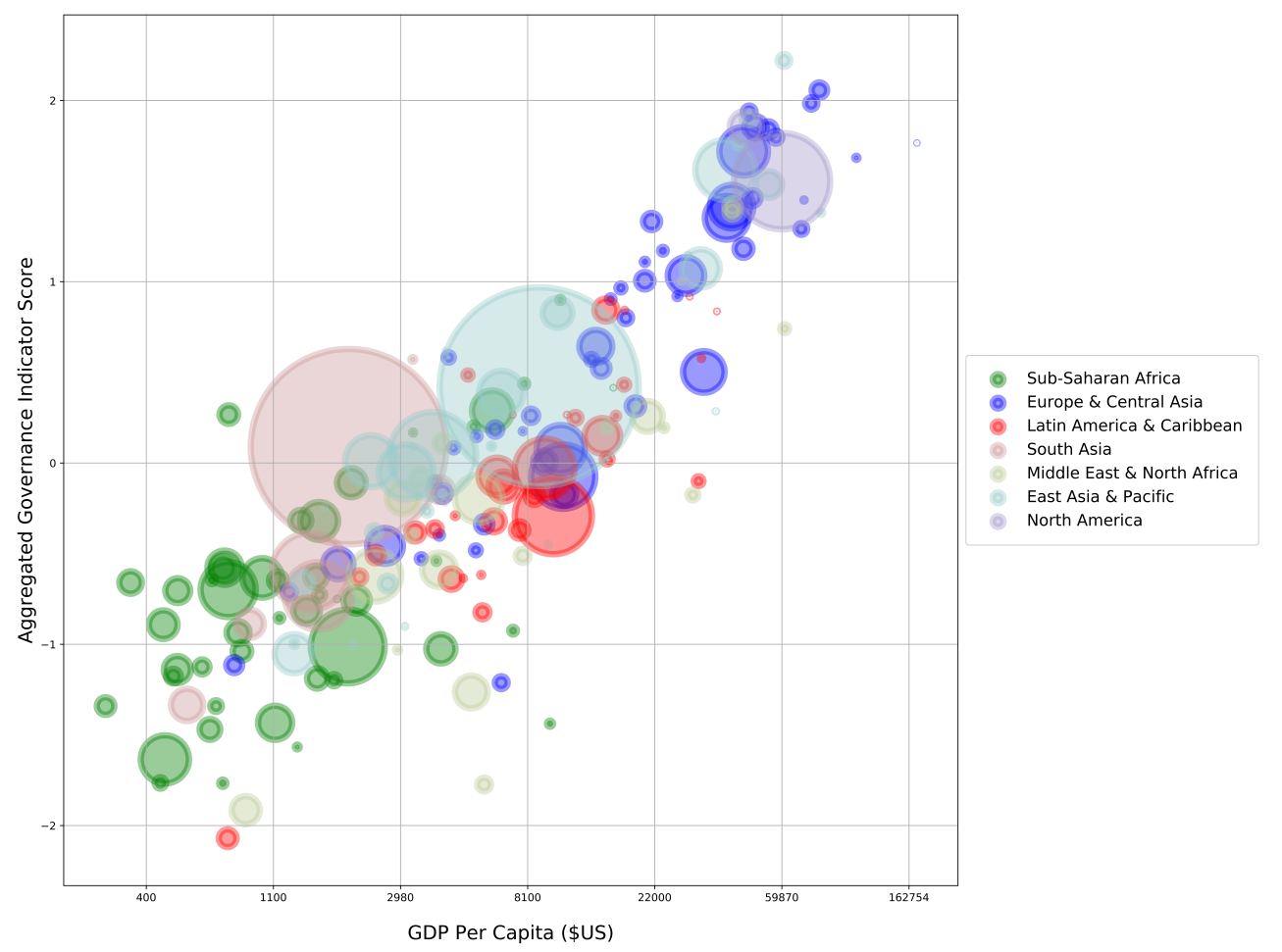

Figure 1. Government Effectiveness based on Worldwide Governance Indicators. Source: [14-16].

Additionally, the capital market development in Africa has been subdued, limiting access to local financing instruments [17]. The size of local stock markets are relatively small comparative to other emerging economies and banking markets are commonly controlled by oligopolistic competition; both are determinants of the high interest rates offered on domestic loans. Other impediments refer to price distortions and information asymmetries [18]. The former refers to broader concerns of poor sector management exemplified by the ongoing subsidization of hydrocarbon projects, perpetuating negative market externalities (energy curtailment by energy producers is common when prices are low) and reducing the competitiveness of renewable energy technologies [19]. 


\subsection{Investor Groups}

Infrastructure finance in Africa is primarily provided by 4 distinct groups of investors: governments, private sector participants, Chinese investors and development finance institutions. Across the continent, contributions by these investors vary, however, external financing (non-domestic) has increased rapidly since 2009. More specifically, the energy sector attracts more than $45 \%$ of total inflows (p. 2, [20]). A significant share of investment is contributed by development finance institutions such as the Infrastructure Finance Corporation (IFC), Asian Development Bank and African Development Bank. Private investments, although constituting a significant share of the Africa's total Foreign Direct Investment (FDI) inflows, have predominantly concentrated to telecommunications industries. Engagement in energy-related projects have been less common and are typical in only a few African countries. Consequently, private sector participation in domestic energy sectors has yet to reach the volumes required to address the increasing concerns of anthropogenic climate change and energy poverty [21].

Additionally, as highlighted in Figure 2, average investment in energy with private participation over the last decade has been lowest in the African region, relative to other low to middle-income economies. The limited investment in energy-related infrastructure relates to the risk-return profiles of domestic projects which, unlike other forms of investment, tend to require significant capital contributions with long-term return profiles [22].

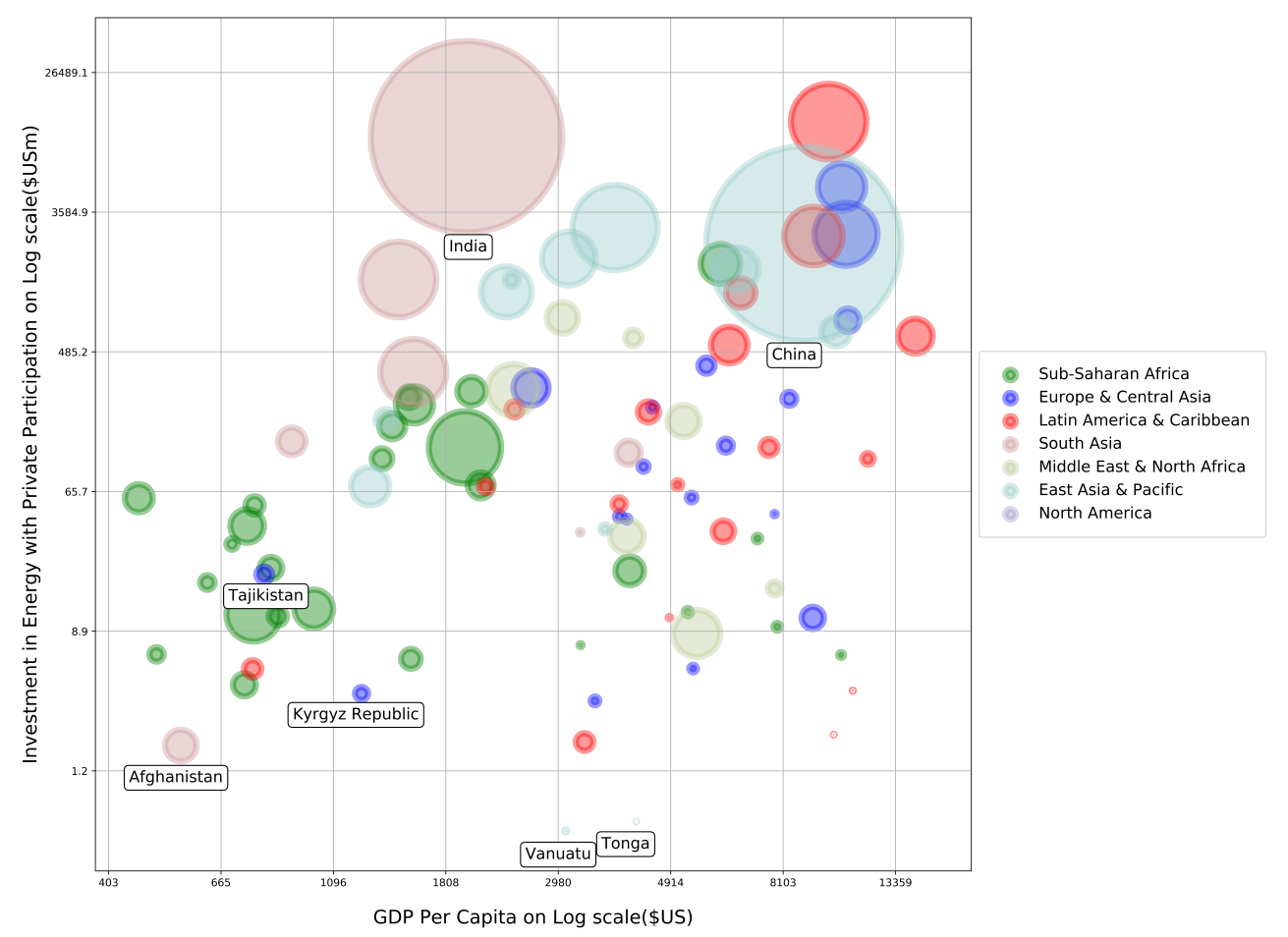

Figure 2. Average Private Participation in Energy Investment on log Scale between 2008-2018. Source: $[14,15,23]$.

Public finance remains the primary source of infrastructure investment in Africa, however, differences in expenditure are notable across the region. Indicators such as the percent of GDP to infrastructure spending distinguish the country-level variance of public services provisions. Research from practitioners suggests, after accounting for the heterogeneity of country-level conditions, infrastructure spending between 5 to $6 \%$ confers socio-economic benefits to nations [20]. State funding varies by approximately $5.6 \%$ of GDP between some African countries [7]. Recent studies indicate few countries in Sub-Saharan Africa (less than 5) provision more than $4 \%$ of GDP to infrastructure [6]. 
Further, the cost recovery ratio and electricity network investment per capita are lower in Africa than in the emerging economies of Brazil, Vietnam, Taiwan and Indonesia (p. 135, [24]).

\subsection{The Decision-Making Problem}

Debates about the best way to remedy the investment deficit have focused on the determinants of actual investment, although acknowledge the limited efficacy of solutions based primarily on public finance [7]. External finance from private investors and development institutions is needed to increase renewable technology development, as well as, to address the shortage of power infrastructure. This view is substantiated by (p. 224, [6]), “...to meet infrastructure investments, African countries must attract more private capital...". Whilst research on private investment in renewable energy has increased over the last decade, there is a general shortage of studies examining the determinants and drivers of these transactions within the context of developing economies [25]. Moreover, even fewer studies have systematically analysed the factors influencing foreign capital investment for renewable energy projects in Africa. Failing to address the antecedents of private sector capital allocation decisions has implications for effective policy design and the success of incentives to accumulate investment in renewable energy sectors [26]. We also argue that addressing the gap in literature requires understanding both financial and non-financial drivers of an investment.

Whilst contemporary financial valuation methods such as the discounted cash flow (DCF) methodology are commonly used to assess the expected financial performance of infrastructure projects [27], non-financial drivers influence the set of opportunities from which a financial project is selected for investment [28]. Omitting the latter group of criteria from analysis, therefore, overlooks an explanation for the historical FDI inflows, to date. Particularly, as perceptions are found to significantly influence the preferences of investors engaging in renewable energy projects [29]. Hence, purely rational economic assessment fails to elucidate the drivers of capital deployment by investors [10]. The authors argue that a decision maker is also influenced by non-financial determinants such as the availability of information and how this information is interpreted based on the interdependence of a-priori beliefs, institutional pressure, knowledge about the operating context and the attitude towards innovation.

Conventional financial valuation models depend on the completeness of objective information and are, therefore, insufficient to quantify fully the effects of non-financial parameters. Developments in the field of multi-criteria decision making have contributed to addressing the vagueness of human emotions in choice outcomes [30]. As a sub-discipline of operations research, MCDM is primarily concerned with developing and designing mathematical tools to support the assessment of alternatives with a limited set of criteria. The application of these methodologies has increased rapidly over the last decade, resulting in broad and interdisciplinary advancements in modelling complex real-world problems [31].

11 MCDM methodologies with unique characteristics and research applications are identified by [32]. Among these methods, Analytical Hierarch Process (AHP), Elimination and Choice Expressing the Reality (ELECTRE) and Preference Ranking Organization method for Enrichment of Evaluation (PROMETHEE) are common in the field of energy planning [33]. Decision-making problems in this area of research depend on inputs from different stakeholders with conflicting objectives, which adds to the complexity of discerning the determinants of choice. Integrating fuzzy set theory in MCDM methodologies addresses some of these challenges; proving well-suited to accounting for the ambiguity of linguistic parameters in experimental designs.

TOPSIS, is a simple and programmable MDCM method that achieves this integration with limited computational cost. A standard TOPSIS method seeks to identify a preferred alternative that has both the farthest distance from a negative ideal solution and shortest distance to a positive ideal solution [34]. Applying fuzzy set theory to the method transforms crisp number values (utilised in standard models) into membership functions whilst preserving the stepwise process utilized to maximize and minimize the evaluation criteria. Fuzzy TOPSIS achieves this transformation and makes 
it possible to use fuzzy number aggregation to calculate the positive ideal solution and negative ideal solution [30]. This finding is substantiated by [33], citing reduction of computational cost and uncertainty as the benefits of fuzzy TOPSIS for addressing energy planning problems. Subsequently, we mobilize the methodology as a tool to addressing the knowledge gap of private investment in African renewable energy projects.

\section{Methodology}

First, we conduct a PESTLE analysis to select 5 African countries as alternatives for a hypothetical renewable energy (RE) project investment. In social sciences PESTLE and its variants, such as the STEEP method, can be used to delineate the impact of macro-environmental factors on the performance of an investment decision $[35,36]$. We examine sixteen macroeconomic and microeconomics indicators, including value chains by clean energy sector, demand dynamics and policy-clean energy to corroborate the relevance of South Africa, Kenya, Nigeria, Cameroon and Tunisia, as ideal alternatives in the study. These countries are identified as leaders in regional indexes examining favorable location-specific characteristics for clean energy investments [37]. Second, the non-financial and financial drivers of investment decision-making are determined by the combined results of expert interviews and a theoretical analysis. We assign these drivers to evaluation criteria based on their economic, political, technical, environment or social aspects. Third, a fuzzy TOPSIS experiment is designed to obtain the order preferences of project attributes and preferred alternatives (countries) from a cohort of 49 investment professionals. Figure 3 outlines the research approach of the paper, which comprises three distinct stages.

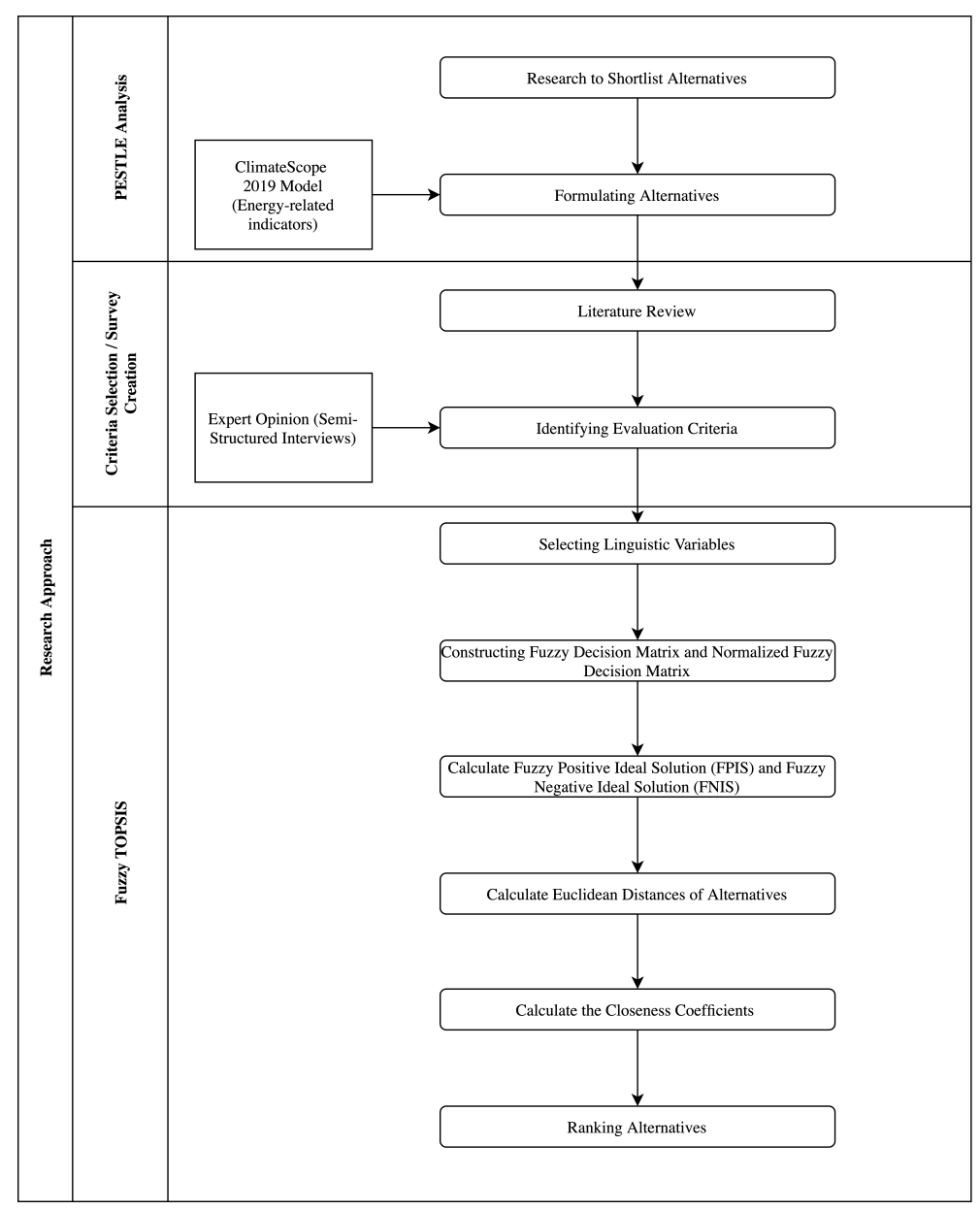

Figure 3. Research Approach. 


\subsection{Fuzzy TOPSIS}

MCDM methodologies are well-suited to the analysis of choice optimization problems in fields of finance, energy analysis and energy planning [38]. The associated methods capture the varying degrees of influence of criteria (both financial and non-financial) and overcome the shortcomings of assessing investment decision-making based exclusively on financial valuation approaches. Incomplete information, increases the relevance of assessing behavioral factors to explain choice outcomes and diminishes forecasting accuracy (p. 405, [9]). The process of identifying an optimal solution from a group of alternatives in a MCDM problem can be summarized in a matrix format [39], as shown in Equation (1).

$$
\begin{gathered}
\mathbf{D}=\begin{array}{c}
C_{1} \\
A_{2} \\
\vdots \\
A_{m}
\end{array}\left(\begin{array}{cccc}
x_{11} & x_{12} & \ldots & c_{1 n} \\
x_{21} & x_{22} & \ldots & x_{2 n} \\
\vdots & \vdots & \vdots & \vdots \\
x_{m 1} & x_{m 2} & \ldots & x_{m n}
\end{array}\right) \\
W=\left[\begin{array}{cccc}
w_{1}, & w_{2}, & \ldots & w_{n}
\end{array}\right]
\end{gathered}
$$

where $D$, denotes the alternatives $\left(A_{1}, A_{2}, \ldots, A_{m}\right)$ selected by a decision-maker based on an evaluation criteria's $\left(C_{1}, C_{2}, \ldots, C_{n}\right)$ corresponding rating, denoted as $x_{i j}$, Further, in group decision-making the rating is aggregated by weightings, $w_{1}, w_{2}, \ldots, w_{n}$ associated to each criterion. In other words, $w_{m}$, captures the significance of a criteria within a group of determinants that represent the preferences of multiple decision-makers. Conventionally, crisp numbers $(\in[0,1])$ are associated to the weightings and ratings of MCDM methodologies, however, are ineffective at interpreting the results derived from the inclusion of linguistic scales in experiments.

Terms such as "Very high importance" replace crisp number representations to overcome the known challenges of evaluating utility functions based on binary number aggregation. However, in order to do so, these functions are restated and interpreted in terms of a matter of degree [40]. In the seminal work of [41], triangular fuzzy set theory is used to improve the interpretation of linguistic Likert scales. By applying this logic to MCDM in a fuzzy TOPSIS approach, the ratings, $x_{i j}$, can be represented by a membership function. Consequently, a criterion with a "Very high importance" rate, normally inputted into the experiment with a crisp number value of 1 , can instead be transformed and represented as the triplet, $(0.9,1,1)$. The transformation of a crisp value utility function using the triangular set theory is shown in Equation (2).

$$
u(k)=\left\{\begin{array}{cc}
0, & k<\alpha_{1} \\
\frac{k-\alpha_{1}}{\alpha_{2}-\alpha_{1}}, & \alpha_{1} \leq k \leq \alpha_{2} \\
\frac{\alpha_{3}-x}{\alpha_{3}-\alpha_{2}}, & \alpha_{2} \leq k \leq \alpha_{3} \\
0, & k>\alpha_{3}
\end{array}\right.
$$

By constructing decision matrices and calculating the distance between the ratings (as triplet values), the fuzzy TOPSIS approach extrapolates both a least and most preferred solution for a given decision problem. Consequently, the distance between an alternative to these two outputs determines an overall order preference, which becomes indicative of a decision-makers optimal choice. Notable implementations of the approach include the works of [39,42], who introduce the following stages in their research design:

1. Linguistic variables are chosen, and the ratings assigned by participants to the evaluation criteria are subsequently aggregated to identify weightings. This step provides the $w_{i}$ and $x_{i j}$ (criteria weight and rating, respectively) as output. 
2. Crisp values $w_{i}$ and $x_{i j}$, for evaluating the alternatives, are assigned triangular fuzzy numbers before being used to construct both a decision matrix and normalised decision matrix, obtained through linear scale transformation.

3. Weightings, from step 1 , are aggregated with the normalised decision matrix to obtain a fuzzy weighted normalized decision matrix.

4. The fuzzy positive-ideal solution (FPIS) and fuzzy negative-ideal solution (FNIS) are calculated by the Euclidean distance of an alternatives criteria to the optimal and least preferred triplet values, shown in Equations (5) and (6).

$$
\begin{gathered}
d(k, l)=\sqrt{\frac{1}{n} \sum_{i=1}^{n}\left[u\left(k_{i}\right)-u\left(l_{i}\right)\right]^{2}} \\
d(k, l)=\sqrt{\frac{1}{3}\left[\left(k_{1}-l_{1}\right)^{2}+\left(k_{2}-l_{2}\right)^{2}+\left(k_{3}-l_{3}\right)^{2}\right]}
\end{gathered}
$$

5. From step 4 , the ideal positive $\left(D^{+}\right)$and ideal negative $\left(D^{-}\right)$distance measurements are calculated. The closeness coefficients provide the alternative ranking and an order of preference based on the proximity of an alternative to the ideal positive and negative solution.

$$
C C_{i}=\frac{D_{i}^{-}}{D_{i}^{+}+D_{i}^{-}}, \quad i=1,2, \cdots, m
$$

The TOPSIS methodology relies extensively on input provided by experts. Specifically, participants with prior knowledge in African renewable energy markets and investment-related transactions provide insight to the pertinent evaluation criteria used in investment decision-making and rank the country alternatives. Semi-structured interviews constitute the primary data collection approach for identifying investment decision-making drivers.

Both $[43,44]$ highlight that effective qualitative studies depend on conducting an optimal number of interviews to obtain a sufficient level of insight to trends and developments within the scope of research. In order to prevent the saturation of knowledge, arising from the collection of increasingly common responses, 14 in-depth interviews were conducted.

The second source of primary data, used to conduct stage 3 of the research methodology, was collected through an online survey based on the existing work of [45]. Non-probability sampling, using online services to both identify and screen participants, was used to source the data. Most of the 49 participants reported that they had more than 5 years of experience in energy or investment-related industries and between 3 to 5 years of experience in working for private firms in the African energy sector. Few responses were collected from industry professionals working in either the non-profit or public sector.

\section{Results}

\subsection{Evaluation Criteria}

The evaluation criteria introduced in the fuzzy TOPSIS approach reflect the combined inputs of a theoretical analysis and qualitative analysis. Whilst extant literature highlights a heterogeneous application of criteria across studies, it is possible to deductively categorise the indicators observed within the corpus into five categories. Namely, economic, environmental, social, technical and political-related issues. Most studies attempted to solve a profit-based optimization problem, relying on cost-based factors and valuation metrics to explain determinants of choice. Economic criteria, therefore, describes the indicators used to assess a renewable energy project's financial performance such as investment cost, cost of imports, NPV, project duration, IRR and taxes $[38,46]$. 
Additionally, the quality of local infrastructure, access to natural resources and environmental impact (measured by $\mathrm{CO}_{2}$ and Nox), frequented as an environmental criteria [47,48]. Studies, which included these indicators, assessed the suitedness of a technology in a specific geography placing attention on the external environment rather than the performance-related consequences of technology deployment. Similarly, the technical criterion enables a comparative assessment of technology feasibility, however, these drivers are independent of location-specificity constraints. The authors in [48], introduce module design and the technical capacity of PV technologies to rank alternative investments. Local labour quality, stakeholder acceptance and the availability of human resources predominated as indicators of social criteria [49].

Finally, very few studies considered the relevance of political issues, however, those examining optimal site selection or determinants of international investment were more likely to do so. Political criteria commonly included risk and security issues, resulting in varying definitions. Specific indicators such as the promotion of private ownership, incentives, investment freedom and corruption emerged across only a select number of studies (see Table 1).

Table 1. Evaluation Criteria References.

\begin{tabular}{lcc}
\hline Aspects & Theoretical Analysis & Interview Response \\
\hline Economic & 84 & 43 \\
Environmental & 70 & 13 \\
Social & 36 & 37 \\
Technical & 44 & 28 \\
Political & 23 & 75 \\
\hline
\end{tabular}

Although, the results of the qualitative analysis reinforce the relevance of economic, environmental, social, technical and political aspects, notable differences are observed in Table 1. First, few interviewees included environmental criteria in their responses. The limited number of references to natural resource abundance and environmental impact is, however, palpably explained by the macro-level context of study. Examining the evaluation criteria used in similar international MCDM studies, focused on country-level decision-making problems, supports the assertion.

Both [50,51], for example, either excluded environmental criteria from their studies or focused on measurements of infrastructure quality to analyse the decision-making determinants of optimal FDI location choices. Second, the political aspects of African renewable energy investments are emphasised in detail throughout the interviews, however, received less attention in the theoretical analysis. Political instability, energy policies, Power Purchase Agreement (PPA) quality, energy market characteristics, Feed-in-Tariffs (FITs), and approval and permits, identified as indicators to assess project feasibility. The emphasis on political factors arguably reflects the expectations of lower government effectiveness and increased uncertainty of project completion in many African countries. Consequently, the evaluation criteria chosen for the fuzzy TOPSIS approach incorporate aspects from each of the five categories, however, particular attention is placed on the political determinants of investments.

Similarly, economic factors are emphasised due to their recurrence during the interviews and in the literature review, conducted as part of the theoretical analysis. A summary of the evaluation criteria included in the fuzzy TOPSIS approach is shown in Table 2. 
Table 2. Overview of Evaluation Criteria.

\begin{tabular}{ll}
\hline Aspects & Criteria \\
\hline Social & C1. Local Demand Characteristics \\
Economic & C2. Macroeconomic Uncertainty \\
& C3. Retail Electricity Prices (USD) \\
& C4. Unlevered Cost of Capital \\
Environmental & C5. Infrastructure Quality \\
Political & C6. PPA Qaulity \\
& C7. Energy Policies and Tax Rate \\
Technical & C8. Energy Market Characteristics \\
& C9. Access to Market Information \\
\hline
\end{tabular}

\subsubsection{Social Criteria}

The social criterion, $\mathrm{C} 1$. Local Demand Characteristics utilizes indicators such as per capita income and national electrification rates to proxy the level of power consumption within a country. In low income economies the cost of energy services constitutes a significant proportion of total monthly household expenditures and, in turn, influences the demand for additional capacity to be connected to the local grid [52].

\subsubsection{Economic Criteria}

Three criteria are introduced to test the pertinence of economic considerations on private investment: C2. Macroeconomic Uncertainty, C3. Retail Electricity Prices (USD) and C4. Unlevered Cost of Capital. Macroeconomic uncertainty, as defined by local currency volatility and inflation, increases a developers financing risks and is expected to influence the investment decision. Additionally, both the unlevered cost of capital and retail electricity prices, are introduced to proxy the financial attractiveness of an investment.

\subsubsection{Environmental Criteria}

The theoretical analysis and qualitative analysis highlights a relationship between the technical capacity and quality of local energy-related infrastructure, and investment performance. The C5. Infrastructure Quality criterion considers the quality of power lines, distribution grids and other energy-related assets as proxies for the complexity of connecting generation assets to local energy grids. Additionally, it is presumed that low infrastructure quality increase the likelihood for energy curtailment and other distribution losses. These indicators may simultaneously influence the financing risks that arise from revenue forecasting errors during planning.

\subsubsection{Political Criteria}

Political risk remains prevalent throughout the African continent and is expected to significantly influence the investment decision. Government Effectiveness is low relative to the rest of the world (see Figure 1) and requires investors to consider the potential impact of political instability, corruption and fragmentation on the performance of a project. To capture these aspects in the fuzzy TOPSIS approach, we introduce C6. Power Purchase Quality, C7. Energy Policies and Tax Rates, and C8. Energy Market Characteristic as political criteria. On the one hand, PPAs encourage private sector participation through revenue-based incentives and provides the contractual arrangements needed to obtain additional security for investment such as guarantees. On the other hand, the efficacy of these arrangements to stimulate investment hinges on regulatory commitment and the likelihood of offtaker risk. Additionally, energy policies, taxes and the energy market characteristics can stimulate private sector participation in the energy sector. Ref. [11], for example, conjecture that regulatory frameworks are necessary antecedents to encourage new investment in generation assets. 


\subsubsection{Technical Criteria}

The C9. Access to Local Market Information criterion refers to the availability of information for an investment and is expected to influence decision-makers as a non-financial driver [10]. Due to the high technical requirements of renewable energy projects, the availability of advisors, technical experts and consultants within a country moderates a private firm's knowledge of the local operating context.

\subsection{Criteria Weights}

Results for the criteria weights were collected from 49 investment professionals with energy-related experience in Africa. The first stage of the survey required participants to rank evaluation criteria based on a Likert scale, ranging from "Very low importance" to "Very high importance" (Table 3).

Table 3. Extract of the Importance Weightings by Evaluation Criteria.

\begin{tabular}{lccccc}
\hline Criteria & $D_{1}$ & $D_{2}$ & $D_{3}$ & $\ldots$ & $D_{49}$ \\
\hline C1. Local Demand Characteristics & $\mathrm{M}$ & $\mathrm{H}$ & $\mathrm{L}$ & $\ldots$ & $\mathrm{VH}$ \\
$\vdots$ & $\vdots$ & $\vdots$ & $\vdots$ & $\vdots$ & $\vdots$ \\
C8. Energy Market Characteristics & $\mathrm{M}$ & $\mathrm{H}$ & $\mathrm{ML}$ & $\ldots$ & $\mathrm{VH}$ \\
C9. Access to Market Information & $\mathrm{MH}$ & $\mathrm{H}$ & $\mathrm{L}$ & $\ldots$ & $\mathrm{MH}$ \\
\hline
\end{tabular}

Based on the survey submissions, the fuzzy weights for each evaluation criteria were calculated. The ranking in Table 4 indicates that PPA quality is considered the most important determinant for assessing projects alternatives, followed by macroeconomic uncertainty and local demand characteristics. Thirty-one respondents in the study rated the importance of the PPA as being of "Very high importance", significantly higher than the 23 responses received for the macroeconomic uncertainty criteria.

Table 4. Extract of Weighted Fuzzy Evaluation Criteria Ratings.

\begin{tabular}{ll}
\hline Criteria & Fuzzy Weight \\
\hline C6. Power Purchase Agreement Quality & $(0.773,0.912,0.963)$ \\
C2. Macroeconomic Uncertainty & $(0.741,0.894,0.965)$ \\
C1. Local Demand Characteristics & $(0.661,0.818,0.914)$ \\
C3. Retail Electricity Prices & $(0.631,0.804,0.918)$ \\
C7. Energy Policies and Tax Rates & $(0.635,0.802,0.904)$ \\
C8. Energy Market Characteristics & $(0.618,0.786,0.890)$ \\
C5. Local Infrastructure Quality & $(0.559,0.739,0.873)$ \\
C4. Unlevered Cost of Capital & $(0.569,0.733,0.851)$ \\
C9. Access to Market Information & $(0.360,0.549,0.720)$ \\
\hline
\end{tabular}

Although the ranking of criteria appears consistent with the findings in the theoretical analysis and amongst the collected interview responses, several intriguing results emerged in the output. The order preference of the equity cost of capital, for example, was inferior to the local retail energy price. Further, local infrastructure quality ranked third last by order of weighting, significantly lower than presumed from both the theoretical analysis and expert interviews.

\subsection{Fuzzy TOPSIS Results}

Both the fuzzy decision matrix and fuzzy weighted normalized decision matrix are derived from the output of the preceding discussion. Having obtained the evaluation criteria weightings, the vector values are aggregated with the ratings assigned by participants for the evaluation criteria of each alternative. Subsequently, the favored solution represents the perceived attractiveness of criteria for a country and the overall importance assigned to an individual criterion based on the group weightings. 
Normalization occurs by calculating the Euclidean distance of each response to the FPIS and FNIS, as both the highest and lowest possible scores attainable from the list of criteria.

Table 5 summarizes the fuzzy Weighted Normalized Decision Matrix. Given the importance of the leading criteria, PPA quality, macroeconomic uncertainty and local demand characteristics, the alternatives with the highest triangular membership function are preferred as investment destinations. The output indicates that individuals prefer the local demand characteristics and PPA quality in South Africa, whereas issues related to macroeconomic uncertainty are less concerning to investors in Kenya. As highlighted in Table 6, these results are also supported by the FPIS and FNIS outputs for each alternative. The preferred country for the renewable energy investment is expected to have the shortest distance from the FPIS (lowest value) and longest distance from the FNIS (highest value).

Table 5. Fuzzy Weighted Normalised Decision Matrix.

\begin{tabular}{lccc}
\hline Criteria & South Africa & Kenya & Nigeria \\
\hline C1. Local Demand Characteristics & $(0.405,0.670,0.890)$ & $(0.324,0.571,0.810)$ & $(0.270,0.492,0.717)$ \\
C2. Macroeconomic Uncertainty & $(0.232,0.454,0.697)$ & $(0.335,0.600,0.848)$ & $(0.167,0.367,0.600)$ \\
C6. PPA Quality & $(0.502,0.777,0.963)$ & $(0.441,0.715,0.923)$ & $(0.250,0.468,0.689)$ \\
C7. Energy Policy and Tax Rate & $(0.250,0.478,0.715)$ & $(0.261,0.496,0.739)$ & $(0.175,0.368,0.602)$ \\
C3. Retail Electricity Price (USD) & $(0.237,0.476,0.739)$ & $(0.290,0.537,0.790)$ & $(0.195,0.408,0.665)$ \\
C8. Energy Market Characteristics & $(0.241,0.472,0.721)$ & $(0.255,0.483,0.715)$ & $(0.142,0.323,0.549)$ \\
C5. Infrastructure Quality & $(0.332,0.588,0.835)$ & $(0.223,0.449,0.711)$ & $(0.092,0.236,0.460)$ \\
C9. Access to Market Information & $(0.210,0.417,0.665)$ & $(0.139,0.32,0.568)$ & $(0.080,0.219,0.441)$ \\
C4. Cost of Equity & $(0.301,0.542,0.791)$ & $(0.277,0.517,0.768)$ & $(0.186,0.383,0.616)$ \\
\hline Criteria & Tunisia & Cameroon & \\
\hline C1. Local Demand Characteristics & $(0.345,0.596,0.819)$ & $(0.225,0.423,0.649)$ & \\
C2. Macroeconomic Uncertainty & $(0.325,0.578,0.811)$ & $(0.165,0.365,0.609)$ & \\
C6. PPA Quality & $(0.376,0.635,0.846)$ & $(0.158,0.345,0.570)$ & \\
C7. Energy Policy and Tax Rate & $(0.244,0.467,0.701)$ & $(0.136,0.316,0.551)$ & \\
C3. Retail Electricity Price (USD) & $(0.221,0.438,0.688)$ & $(0.196,0.403,0.650)$ & \\
C8. Energy Market Characteristics & $(0.221,0.438,0.688)$ & $(0.139,0.330,0.572)$ & \\
C5. Infrastructure Quality & $(0.221,0.438,0.688)$ & $(0.088,0.240,0.476)$ & \\
C9. Access to Market Information & $(0.139,0.320,0.566)$ & $(0.056,0.176,0.387)$ & \\
C4. Cost of Equity & $(0.205,0.403,0.630)$ & $(0.164,0.356,0.603)$ & \\
\hline
\end{tabular}

Table 6. FPIS and FNIS for Country Alternatives.

\begin{tabular}{lccccc}
\hline Criteria & South Africa & Kenya & Nigeria & Tunisia & Cameroon \\
\hline Fuzzy Positive Ideal Solution (FPIS) & 4.50993 & 4.62260 & 5.83014 & 4.87493 & 6.08553 \\
Fuzzy Negative Ideal Solution (FNIS) & 5.18261 & 5.02908 & 3.72944 & 4.76483 & 3.47715 \\
\hline
\end{tabular}

The closeness coefficients for each country are calculated as the final stage of the fuzzy TOPSIS analysis. Figure 4 plots the combined results of these outputs. Consequently, South Africa is identified as the preferred investment destination for renewable energy projects based on the survey responses and the evaluation criteria introduced in the study. Kenya ranked second, followed by Tunisia, Nigeria and Cameroon, respectively. 


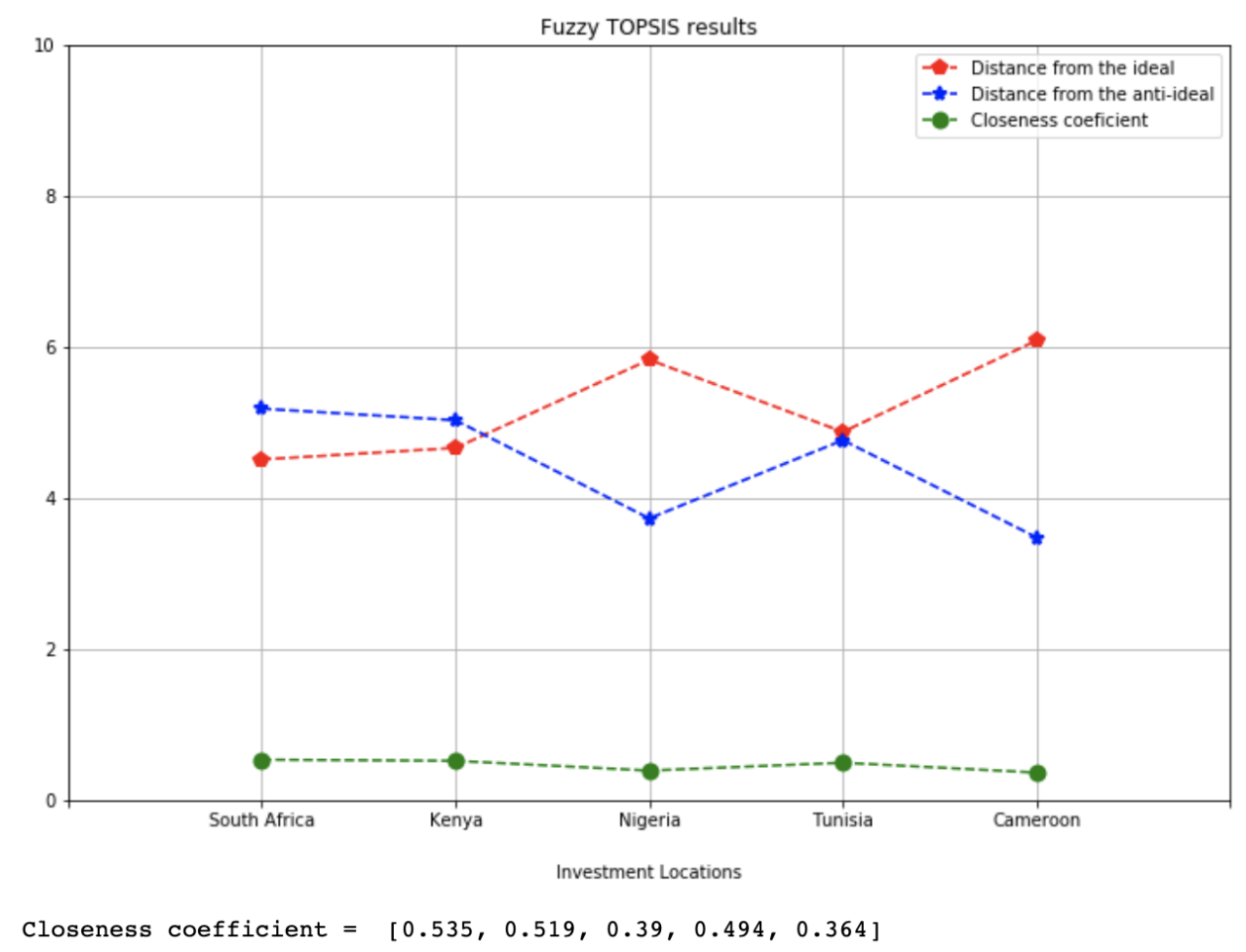

Figure 4. Fuzzy TOPSIS Results.

In addition to the order preference of alternatives, differences between objective indicator values, their expected ratings and the actual response from participants are observable. South Africa, which has preferential local demand characteristics and a low unlevered cost of capital relative to the alternatives should, for example, rank as the preferred alternative in these categories. More specifically, the order preference of alternatives presumably follows a symmetrical ranking between the rating of the evaluation criteria and the presented indicators. Whilst the assertion upholds in this example, asymmetries are also identified in several areas.

First, variances in the expected results emerged whenever an evaluation criterion contained identical indicator values for several alternatives. The countries, Kenya, Nigeria and Tunisia had the same indicator values for PPA quality. Our fuzzy weighted normalized decision matrix, however, signifies a large variance in the fuzzy triangular numbers: $(0.441,0.715,0.923),(0.250,0.468,0.689)$ and $(0.376,0.635,0.846)$, respectively. Second, whilst the PPA quality rating in South Africa should be inferior relative to the other alternatives, the results failed to promulgate the relationship.

Instead, South Africa received the highest rating for this criterion as exemplified by the membership function, $(0.502,0.777,0.973)$. The results are interesting for several reasons. Foremost, whilst Kenya, Nigeria and Tunisia offer standardized contracts in both local and foreign currency, South Africa provides similar contracts in local currency, only [37]. When PPAs cannot be denominated in hard currencies such as EUR and USD, investors are susceptible to increased financing risk arising from foreign exchange liabilities. Additionally, although participants reported greater concern for macroeconomic uncertainty in South Africa than in Kenya and Tunisia, the results seem inconsistent. Subsequently, the findings suggest that additional drivers, excluded from the study, were also considered in responses. Whilst indicators capturing the likelihood of contract renegotiations and regulatory commitment were purposefully excluded from analysis (due to data limitations), it is palpable that such issues took precedence in responses.

\section{Discussion and Conclusions}

Several interesting findings related to the non-financial and financial determinants of investments in African renewable energy projects are highlighted in the paper. Foremost, the quality of regional 
PPAs significantly moderates a decision-maker's choice of investment. Of the nine evaluation criteria introduced in the study, the policy-related issues embedded in contractual arrangements preside as the primary concern for investment decisions. Determinants such as macroeconomic uncertainty and local demand characteristics are also identified as pertinent variables in the study. The ratings assigned to the evaluation criteria highlight that valuation indicators such as the cost of capital are considered less significant during the early stages of the decision process.

Further, the rankings of the alternative country locations are mostly consistent with the assumed order preference derived from the indicator values of the nine evaluation criteria. Specifically, participants correctly identified the preferred solution (alternative) based on rational expectations. Countries with preferential conditions for leading criteria were also more likely to be given a higher rating by the decision makers. Inconsistencies emerged, however, whenever the values associated to an evaluation criteria were identical for two or more countries.

Finally, our findings are in line with the seminal work of [10]. Although their econometric analysis of behavioral factors in energy investments was tested on 135 European investors, we find several similarities in the results of the fuzzy TOPSIS study. First, the expert interviews and order preferences corroborate the relevance of a priori beliefs, institutional pressure, attitude towards technological innovation and knowledge of the RE operational context as non-financial drivers. Second, an investor's confidence in the effectiveness of existing policies and confidence in technology adequacy both influence the capital allocation decision for renewable energy projects. However, whilst the conceptual model suggests that the latter takes precedence over the former, our findings suggest otherwise. Beliefs about the effectiveness of policies predominates as a pertinent evaluation criterion used by investors to evaluate investments in African energy infrastructure. Country and regional heterogeneities, including issues related to the complexity of the business environment and macroeconomic environment are compelling arguments to explain the observed differences.

\subsection{Confidence in Policies}

Investor confidence in policies has been promulgated extensively throughout the paper as a cause for the perceived absence of investment opportunities throughout Africa. Solutions to the energy investment gap requires addressing regional realities, including comparatively low government effectiveness. Further, the high degree of bundled ownership in energy markets has resulted in skill and knowledge shortages for the development of effective renewable energy sectors, hindering the confidence instilled by investors when examining potential investment locations. Several remedies to the current challenges are conjectured.

First, due to the low energy sector privatization in many African countries, government preferences determine the competitiveness of different power infrastructure technologies. Subject to the co-movement of oil and renewable energy prices, and exacerbated by poor governance, it is not surprising to evidence changes in contracted PPAs over time. As such, aligning private sector objectives to domestic policies is pertinent to achieve cooperation with local stakeholders, and to mitigate political interference. Further, these factors also influence energy sector development: frequent changes to targets and policies slow technological progress. In order to address the adverse consequences of market imperfections on FDI inflows, governments are tasked with establishing markets for renewable energy. Stimulating the demand-side eliminates institutional rigidities from power infrastructure investments. In India, Renewable Energy Certificates (RECs), have been used to encourage the production of power from sustainable sources [53]. These certificates (or credits) are traded via digital marketplaces, facilitating a competitive environment for trade. Consequently, the use of RECs augments the preferences for renewable energy investments and, partially, reduces the significance of issues related to an investors confidence in policy effectiveness.

Second, investment in local capacity building is encouraged to enhance the effectiveness of PPA contracts in bi-lateral and tender agreements. The development of local skills reduces regulatory dependence on external advisors to facilitate effective bidding rounds and, simultaneously, improves 
the business environment for new entrants. Ref. [11] posit that skills shortages in the energy sector cause costly delays, administrative bottlenecks, incoherent frameworks and contracting issues. Improving confidence in policies is also considered tantamount to the enhancement of knowledge in energy sectors. In this regard, there is a compelling opportunity to contribute to renewable energy development in Africa. Companies and institutions which support regulators in the development of skills, tools and knowledge, can contribute to addressing the barriers for private sector participation.

Third, we posit that an interrelationship exists between investor confidence in policies and the financial risk exposure of developers during construction and operation stages. During pre-operation, the equity and debt capital allocated to a project must exceed all expected cash outflows. Simultaneously the availability of financial resources is contingent on the quality of the agreements conferred to the energy provider in a local jurisdiction. Consequently, enhancement of the perceived attractiveness of an investment destination, hereby referring to non-financial drivers of investment decisions, improves a generators ability to procure financing at lower cost. Or, improves the sources of capital available to the investor. Remedying the determinants of confidence in policy effectiveness not only improves the perception of alternatives by the decision maker but has spillover effects on the nexus of stakeholders included in the project. Lower costs of capital, resulting from the perceived reduction in uncertainty, for example, can encourage new private sector participants into African economies.

The Gordian knot which plagues Africa is unlikely to unravel without institutional change. In India, setting up integrated arrangements for promoting renewable energy sources proved effective in bypassing institutional rigidities [53]. As such, the paper also addresses the need for investors to adopt valuation methodologies, which capture risk differences throughout project development stages (during planning, operation and construction). Risk-adjusted discount rates and assumptions in a DCF model are identified as a possible methods to capture the variability of financing risks throughout the different stages of project development. Additionally, the paper highlights the benefits of quantifying drivers and areas of uncertainty to understand better the issues impacting a decision-makers choice. Given the simplicity of designing and conducting a MCDM analysis, practitioners are encouraged to integrate the results of these methodologies into financial models and existing assessment procedures. By delineating the expected weightings and importance of financial inputs, methodologies such as the fuzzy TOPSIS prove useful in explicating the macroeconomic issues impacting the performance of a project.

\subsection{Limitations and Areas of Further Research}

Although the paper provides valuable results, highlighting several issues pertaining to Africa's infrastructure investment gap, its macroeconomic scope of analysis imposes limitations on the research findings. First, different renewable technology attributes, including capacity and cost, are important considerations affecting investments in power infrastructure. Assessing the suitability of wind, solar and thermal projects is, therefore, achieved by relying on different evaluation criteria, excluded from the research approach. The omission of location-specific infrastructure issues makes it difficult to evaluate technology options in the optimal investment location. Assessing investor preferences for different technologies in African economies constitutes an important area of research as technology adequacy and innovation are expected to moderate a decision-makers choice.

Second, findings from the fuzzy TOPSIS analysis are generalized to elucidate the challenges of renewable energy projects in Africa. Both arguments in favour of and against the homogeneity of countries throughout the continent are considered. Arguably, however, the heterogeneity between countries, including those in the same regions, is difficult to overlook. Delineating the specific issues related to investor confidence in policies, in the form of PPA quality, is an important finding of the paper. Studies examining energy policy effectiveness, and PPA quality, in country-specific case studies would, however, contribute significantly to the present discussion.

Thirdly, because the paper utilises a private-sector perspective, profit maximization arguments are predominately used to address the research question. Given the added social cost of infrastructure 
projects, analysing the viewpoints of government and the decision-making determinants of the public sector would also be of value. Interestingly, ref. [54], has alluded to the conflicting interests of regulators during periods of uncertainty. Countries identified as laggards of socio-economic development are often constrained by conflicting priorities, which likely exacerbate the poor policy effectiveness concerns of investors.

\subsection{Conclusions}

A growing body of research posits the necessity for private sector participation in African power sectors in order to encourage renewable energy development and to address perpetuating investment gaps. Presently, public funding in the region is not sufficient to provide basic energy services and to match the expected increase in demand correlated with population growth in the coming decades. Consequently, large African populations still rely on unsustainable captive hydrocarbon energy solutions for industrial application, and biofuels for household use. The lack of infrastructure remains a cause of Africa's subdued socio-economic development.

Whilst external financing of power infrastructure has increased in recent years due to the progressive movement of power sector reform, private sector participation in African energy projects is still low relative to other low-to-middle income economies. Macroeconomic and microeconomic constraints explain the comparatively small number of privately funded power infrastructure. High levels of economic uncertainty, low government effectiveness and the concentration of state ownership in the sectors increase the complexity of developing these projects in African economies. Whilst uncertainty is coalesced in the risk-reward profiles of local energy projects, these factors also influence the non-financial drivers through which investors make choices. In particular, the dissemination of information by a decision-maker depends on the interpretation of country or project-specific criteria through personal beliefs, attitudes and knowledge of the local environment. Despite the evidence that non-financial drivers matter to explain investor behaviour in renewable energy projects, the relevance of these factors in an African context has received limited attention.

The paper addresses the knowledge gap by delineating the non-financial and financial determinants of private investment in African renewable energy. Understanding the links between these categories and their influence on investment decisions is necessary to predicate policy recommendations. We used nine broad evaluation criteria that capture financial and non-financial drivers of an investment. Our findings reveal that political criteria predominate as primary indicators for investors when examining country-level indicators of project feasibility. Issues related to government effectiveness, the presence of energy policies, PPA quality, energy market characteristics and approvals contribute to the challenge of renewable energy infrastructure development in Africa.

Experts rated the importance of 9 evaluation criteria and ranked the attractiveness of 5 African countries for a hypothetical renewable energy infrastructure investment. Of these criteria, PPA quality ranked highest by the degree of importance, followed by macroeconomic uncertainty and local demand characteristics, respectively. The cost of capital and the quality of local infrastructure ranked lower than expected. It is palpable that investors considered the certainty of infrastructure-related challenges in emerging economies less significant than the consequences of unexpected events and interference on project performance. Further, of the 5 African countries in the experiment, South Africa emerged as the preferred investment destination for renewable energy projects, followed by Kenya, Tunisia, Nigeria and Cameroon, respectively.

Our findings indicate that investor confidence in policy effectiveness moderates the investment decision more in Africa, relative to Western alternatives. We propose several solutions to address these differences and the interdependence between policy-related evaluation criteria such as PPA quality and the outcome of the MCDM experiment. First, we posit the importance of local capacity building through the provision of resources to acquire skills and knowledge in energy sector development, effective policy frameworks and contracts, as signalling effects for improvements to regulatory commitment. Enhancing the effectiveness of bi-lateral contract and tender rounds encourages the 
development of local renewable energy industries directly and influences the perceptions of external investors. Second, stimulating demand-side pressure can disintermediate areas of government tasked with encouraging renewable energy development. Trading these contracts on exchanges both increases the competitiveness of renewable energy technologies and mitigates institutional rigidities, which contribute to the perceived lack of policy confidence.

Enhancing the indicators through which criteria such as PPA quality and macroeconomic uncertainty are interpreted by private investors can significantly contribute to resolving Africa's power infrastructure gap. In short, presenting projects in a manner that is palatable to international alternatives is just part of the solution. Ensuring regulatory commitment is critical to remedy the legacy of beliefs about uncertainty throughout the continent.

Author Contributions: All authors contributed equally to the work. All authors have read and agreed to the published version of the manuscript.

Funding: Financial support from the Copenhagen School of Energy Infrastructure (CSEI) is acknowledged. The activities of CSEI are funded jointly in cooperation between CBS and partners from the energy sector. The funders had no role in the design of the study; in the collection, analyses, or interpretation of data; in the writing of the manuscript, or in the decision to publish the results.

Conflicts of Interest: The authors declare no conflict of interest.

\section{References}

1. Avila, N.; Carvallo, J.P.; Shaw, B.; Kammen, D.M. The energy challenge in sub-Saharan Africa: A guide for advocates and policy makers: Part 1: Generating energy for sustainable and equitable development. Oxfam Res. Backgrounder Ser. 2017, 1, 1-78.

2. Wolde-Rufael, Y. Electricity consumption and economic growth: A time series experience for 17 African countries. Energy Policy 2006, 34, 1106-1114. [CrossRef]

3. Oyedepo, S.O. On energy for sustainable development in Nigeria. Renew. Sustain. Energy Rev. 2012, 16, $2583-2598$. [CrossRef]

4. Kaygusuz, K. Energy for sustainable development: A case of developing countries. Renew. Sustain. Energy Rev. 2012, 16, 1116-1126. [CrossRef]

5. Bhattacharya, A.; Kojima, S. Power sector investment risk and renewable energy: A Japanese case study using portfolio risk optimization method. Energy Policy 2012, 40, 69-80. [CrossRef]

6. EIB. Banking in Africa: Delivering on Financial Inclusion, Supporting Financial Stability; European Investment Bank: Luxembourg, 2018; pp. 1-232.

7. Eberhard, A.; Rosnes, O.; Shkaratan, M.; Vennemo, H. Africa's Power Infrastructure: Investment, Integration, Efficiency; The World Bank: Washington, DC, USA, 2011.

8. Imam, M.I.; Jamasb, T.; Llorca, M. Sector reforms and institutional corruption: Evidence from electricity industry in Sub-Saharan Africa. Energy Policy 2019, 129, 532-545. [CrossRef]

9. Zopounidis, C. Multicriteria decision aid in financial management. Eur. J. Oper. Res. 1999, 119, 404-415. [CrossRef]

10. Masini, A.; Menichetti, E. Investment decisions in the renewable energy sector: An analysis of non-financial drivers. Technol. Forecast. Soc. Chang. 2013, 80, 510-524. [CrossRef]

11. IFLR. International Financial Law Review; Project Finance Report 2017; IFLR: London, UK, 2017; p. 58.

12. Gastanaga, V.M.; Nugent, J.B.; Pashamova, B. Host country reforms and FDI inflows: How much difference do they make? World Dev. 1998, 26, 1299-1314. [CrossRef]

13. Cleeve, E. Political and institutional impediments to foreign direct investment inflows to Sub-Saharan Africa. Thunderbird Int. Bus. Rev. 2012, 54, 469-477. [CrossRef]

14. World Bank. World Development Indicators: GDP Per Capita (Current US\$); The World Bank Group: Washington, DC, USA, 2020.

15. World Bank. World Development Indicators: Population, Total; The World Bank Group: Washington, DC, USA, 2020.

16. World Bank. Worldwide Governance Indicators: Government Effectiveness; The World Bank Group: Washington, DC, USA, 2020. 
17. Gabriel, C.A. What is challenging renewable energy entrepreneurs in developing countries? Renew. Sustain. Energy Rev. 2016, 64, 362-371. [CrossRef]

18. Painuly, J.P. Barriers to renewable energy penetration; a framework for analysis. Renew. Energy 2001, $24,73-89$. [CrossRef]

19. Al-mulali, U.; Fereidouni, H.G.; Lee, J.Y. Electricity consumption from renewable and non-renewable sources and economic growth: Evidence from Latin American countries. Renew. Sustain. Energy Rev. 2014, 30, 290-298. [CrossRef]

20. Gutman, J.; Sy, A.; Chattopadhyay, S. Financing African Infrastructure: Can the World Deliver; The Brookings Institution: Washington, DC, USA, 2015.

21. Hoch, S.; Friedmann, V.; Michaelowa, A. Mobilising Private-Sector Investment to Mitigate Climate Change in Africa; Stockholm Environment Institute: Stockholm, Sweden, 2018.

22. UNCTAD, U. World investment report 2014: Investing in the SDGs: An action plan. U. N. Publ. Retrieved May 2014, 5, 2015.

23. World Bank. Private Participation in Infrastructure Project Database: Investment in Energy with Private Participation (Current US\$); The World Bank Group: Washington, DC, USA, 2020.

24. IRENA. Renewable Power Generation Costs in 2018; International Renewable Energy Agency: Abu Dhabi, UAE, 2019.

25. Ragosa, G.; Warren, P. Unpacking the determinants of cross-border private investment in renewable energy in developing countries. J. Clean. Prod. 2019, 235, 854-865. [CrossRef]

26. Wüstenhagen, R.; Menichetti, E. Strategic choices for renewable energy investment: Conceptual framework and opportunities for further research. Energy Policy 2012, 40, 1-10. [CrossRef]

27. Titman, S.; Grinblatt, M. Financial Markets and Corporate Strategy; The McCraw-Hill: New York, NY, USA, 1998.

28. Spronk, J.; Hallerbach, W. Financial modelling: Where to go? With an illustration for portfolio management. Eur. J. Oper. Res. 1997, 99, 113-125. [CrossRef]

29. Meijer, I.S.; Hekkert, M.P.; Faber, J.; Smits, R.E. Perceived uncertainties regarding socio-technological transformations: towards a framework. Int. J. Foresight Innov. Policy 2006, 2, 214-240. [CrossRef]

30. Kahraman, C.; Kaya, İ; Cebi, S. A comparative analysis for multiattribute selection among renewable energy alternatives using fuzzy axiomatic design and fuzzy analytic hierarchy process. Energy 2009, 34, 1603-1616. [CrossRef]

31. Behzadian, M.; Otaghsara, S.K.; Yazdani, M.; Ignatius, J. A state-of the-art survey of TOPSIS applications. Expert Syst. Appl. 2012, 39, 13051-13069. [CrossRef]

32. Velasquez, M.; Hester, P.T. An analysis of multi-criteria decision making methods. Int. J. Oper. Res. 2013, 10, 56-66.

33. Ervural, B.C.; Zaim, S.; Demirel, O.F.; Aydin, Z.; Delen, D. An ANP and fuzzy TOPSIS-based SWOT analysis for Turkey's energy planning. Renew. Sustain. Energy Rev. 2018, 82, 1538-1550. [CrossRef]

34. Chen, S.J.; Hwang, C.L. Fuzzy multiple attribute decision making methods. In Fuzzy Multiple Attribute Decision Making; Springer: Berlin/Heidelberg, Germany, 1992; pp. 289-486.

35. Chou, C.C.; Yu, K.W. Application of a new hybrid fuzzy AHP model to the location choice. Math. Probl. Eng. 2013, 2013. [CrossRef]

36. Zalengera, C.; Blanchard, R.E.; Eames, P.C.; Juma, A.M.; Chitawo, M.L.; Gondwe, K.T. Overview of the Malawi energy situation and A PESTLE analysis for sustainable development of renewable energy. Renew. Sustain. Energy Rev. 2014, 38, 335-347. [CrossRef]

37. BloombergNEF. Climatescope 2019; Bloomberg Finance L.P.: New York, NY, USA, 2018.

38. Afsordegan, A.; Sánchez, M.; Agell, N.; Zahedi, S.; Cremades, L.V. Decision making under uncertainty using a qualitative TOPSIS method for selecting sustainable energy alternatives. Int. J. Environ. Sci. Technol. 2016, 13, 1419-1432. [CrossRef]

39. Chen, C.T. Extensions of the TOPSIS for group decision-making under fuzzy environment. Fuzzy Sets Syst. 2000, 114, 1-9. [CrossRef]

40. Kahraman, C.; Kaya, I. A fuzzy multicriteria methodology for selection among energy alternatives. Expert Syst. Appl. 2010, 37, 6270-6281. [CrossRef]

41. Yong, D. Plant location selection based on fuzzy TOPSIS. Int. J. Adv. Manuf. Technol. 2006, 28, 839-844. [CrossRef]

42. Papathanasiou, J.; Ploskas, N. Multiple Criteria Decision Aid; Springer: Berlin/Heidelberg, Germany, 2018. 
43. Guest, G.; Bunce, A.; Johnson, L. How Many Interviews Are Enough?: An Experiment with Data Saturation and Variability. Field Methods 2006, 18, 59-82. [CrossRef]

44. Bertaux, D. From the life-history approach to the transformation of sociological practice. Sage Stud. Int. Sociol. 1981, 23, 29-45.

45. Nazari, M.A.; Aslani, A.; Ghasempour, R. Analysis of solar farm site selection based on TOPSIS approach. Int. J. Soc. Ecol. Sustain. Dev. 2018, 9, 12-25. [CrossRef]

46. Georgopoulou, E.; Sarafidis, Y.; Diakoulaki, D. Design and implementation of a group DSS for sustaining renewable energies exploitation. Eur. J. Oper. Res. 1998, 109, 483-500. [CrossRef]

47. Choudhary, D.; Shankar, R. An STEEP-fuzzy AHP-TOPSIS framework for evaluation and selection of thermal power plant location: A case study from India. Energy 2012, 42, 510-521. [CrossRef]

48. Azzopardi, B.; Martínez-Ceseña, E.A.; Mutale, J. Decision support system for ranking photovoltaic technologies. IET Renew. Power Gener. 2013, 7, 669-679. [CrossRef]

49. Athawale, V.M.; Chatterjee, P.; Chakraborty, S. Decision making for facility location selection using PROMETHEE II method. Int. J. Ind. Syst. Eng. 2012, 11, 16-30. [CrossRef]

50. Karimi, M.S.; Yusop, Z.; Law, S.H. Location decision for foreign direct investment in ASEAN countries: A TOPSIS approach. Int. Res. J. Financ. Econ. 2010, 36, 196-207.

51. Andreea, P.; Popovici, A.C.; Călin, C.A. The attractiveness of CEE countries for FDI. A public policy approach using the TOPSIS method. Transylv. Rev. Adm. Sci. 2014, 10, 156-180.

52. IEA. Africa Energy Outlook 2019; International Energy Agency: Paris, France, 2019.

53. Sen, A.; Jamasb, T. Diversity in unity: an empirical analysis of electricity deregulation in Indian states. Energy J. 2012, 33. [CrossRef]

54. Nee, V. Organizational dynamics of market transition: Hybrid forms, property rights, and mixed economy in China. Adm. Sci. Q. 1992, 37, 1-27. [CrossRef]

Publisher's Note: MDPI stays neutral with regard to jurisdictional claims in published maps and institutional affiliations.

(C) 2020 by the authors. Licensee MDPI, Basel, Switzerland. This article is an open access article distributed under the terms and conditions of the Creative Commons Attribution (CC BY) license (http:/ / creativecommons.org/licenses/by/4.0/). 